10 years ESJ

Special edition

\title{
Reforms in Times of Crisis: Notes on the Greek Policy Making from Bankruptcy to COVID-19
}

\author{
Ioannis Balampanidis, PhD in Political Science \\ Centre for Political Research / Department of Political Science and History, \\ Panteion University of Social and Political Sciences \\ Sotiria Liakaki, PhD in Philosophy \\ Independent Researcher
}

Doi: 10.19044/esj.2021.v17n31p33

Submitted: 28 May 2021

Accepted: 06 September 2021

Published: 15 September 2021
Copyright 2021 Author(s)

Under Creative Commons BY-NC-ND

4.0 OPEN ACCESS

Academic Editors: Georgios Farantos \& Nikitas-Spiros Koutsoukis

Cite As:

Balampanidis I. \& Liakaki S. (2021). Reforms in Times of Crisis: Notes on the Greek Policy Making from Bankruptcy to COVID-19. European Scientific Journal, ESJ, 17 (31), 33.

https://doi.org/10.19044/esj.2021.v17n31p33

\section{Abstract}

In this paper, an in-depth quantitative and qualitative analysis of the "emergency" regulation in Greece over the years of acute economic crisis and up to the COVID-19 public health crisis is performed, to examine if this kind of regulation has been too extended and whether it undermined any effective policy design. According to our working hypothesis, the "fast-track" legislation highlights the fragmented and somewhat erratic way of policymaking in Greece, while it also affirms the country's limited capacity to properly initiate and implement reforms. Thus, the paper focuses on the collection and evaluation of the legislative corpus during the 2009-2021 period; its objective being, on the one hand, to evaluate whether and how much each government resorted to the invocation of urgency and on the other hand to examine the documentation and description of the legislative process vis-àvis the imperatives and quality criteria of Better Regulation and EvidenceBased Policy Making. At the same time, the article focuses on legislative texts of the 2020-2021 COVID-19 health crisis period. It will showcase the latter as an additional trigger aggravating the "urgency" element of regulation, transforming it into a persistent feature of Greek policymaking. Ergo, we examine methods and practices at the international level, focusing especially 
on the Evidence-Based Policy Making paradigm. Based on the analysis of the crisis regulation and international EBPM best practices, the paper concludes with key recommendations for an effective policymaking procedure, dependent on the establishment of an integrated Center of Government in Greece.

Keywords: Evidence-based policymaking, public policy, Better Regulation, Core of Government, reforms, economic crisis, COVID-19

\section{Introduction}

In the context of the economic crisis of 2009 in Greece, fiscal consolidation programs brought about a sweeping pack of policy reforms, which the Greek governments of the past decades were thought to be lacking the ability or the will to implement. The entire policy framework imposed based on the Memoranda looks like an attempt to "rebuild the ship at sea" (Elster, Offe, Preuss, 1998). However, this reform and policy package was interlinked to stifling budgetary requirements and was eventually implemented through resorting to a "state of (fiscal and economic) emergency" legislation. The cycle of austerity programs formally closed in 2018, with the completion of the third Memorandum. Very soon, a new cycle of crisis and "state of emergency" would open, this time of public health in character, due to the COVID-19 pandemic, albeit with clear budgetary implications. The country thus has undergone more than a decade of ongoing crisis (2009-2021).

In the early years of the crisis, an intense and often polemic public controversy has developed in Greece on the marginally constitutional character of the implementation of memorandum policies via urgent bills or

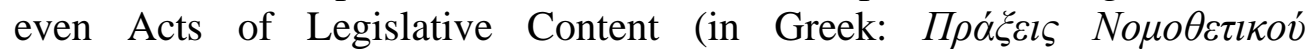

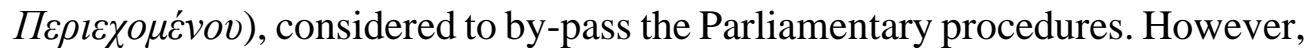
it is also necessary to go beyond this view, which overshadowed a different debate that was never held in the public sphere over those years, and which would possibly be more substantial. More specifically, one should wonder if this regime of "extraordinary" legislation, regulation and policymaking, was compatible with an effective reform program that Greece needed to overcome its crisis. In this paper, we aim to pose the question that has precisely remained in the shadow of public and political controversy: How effective was this "extraordinary legislation" in the context of the adjustment program, and also compared to the framework of the health crisis of 2020, in terms of planning and implementing public policies? What could or should have been done differently?

At this point, the debate on "regulation in a state of emergency" is interwoven with a question that has been the subject of public debate and 
scientific literature for years: "Why do reforms fail in Greece?" Various responses have been proposed from time to time. This failure has sometimes been attributed to the almighty political parties in contrast to a weak civil society and institutional checks and balances (Mouzelis, 2005). Others emphasize the clientelistic political model of the Greek post-dictatorial era (Metapolitefsi) or a certain interconnection between politicians, parties, and specific interest groups that hinders reforms and public policies for selfserving purposes (Iordanoglou, 2013). Another argument stresses the internal constraints connected to a certain spirit of resistance to reforms and Europeanisation (Featherstone \& Papadimitriou, 2010).

Greek society is seen as a "blocked society" (Featherstone, 2005). It is often considered that the state administration and political elites in Greece are governed by a "passive-responsive" rather than "active-intended" spirit of response to the demands of Europeanisation (Ioakimidis, 2001), as powerful veto-players hinder the reforms that would upset the established interests (Tsebelis, 2002). Similarly, comparative approaches point out that in Greece, as in other southern European countries, the clientelist tradition, legislative formalism, and implementation gap are inhibiting factors for state modernization (Sotiropoulos, 2007). However, in this literature seldom is the failure of reforms related to how the legislation, namely regulation and public policies, is being planned, drafted, and implemented.

This very subcutaneous aspect of the Greek crisis is at the heart of this paper, which draws from an extended study that the authors have conducted and published in Greek (Liakaki \& Balampanidis, 2019). It is first and foremost a critical aspect, especially as the policies imposed on Greece by "the Troika", i.e. a particularly strong exogenous pressure for institutional reforms (Ladi, 2012), found virtually no acceptance and legitimacy within the country or among the political parties and citizens. This was the case not only because of the more or less foreseeable consequences of a harsh fiscal adjustment (economic recession and social depression) but also to the extent that even certain aspects of crucial state and economy rationalization were not perceived as "owned" by the Greek political elites, public administration, social partners and civil society.

The working hypothesis of this paper is thus the following: the economic and financial crisis, as well as the COVID-19 health crisis, introduced an "emergency" legislation as a quasi-permanent characteristic of the public policymaking in Greece. This has been controversial in terms of regulatory quality (Better Regulation) and thus largely ineffective in terms of public policy design. We suggest that this double-sided picture could be another possible answer to the question "Why do reforms fail in Greece?". The meaning of the term "reform" here is not limited to an exclusively fiscal and broader economic nature (as would reasonably be the case in an economic 
crisis) but also pertains to numerous public policy fields, such as education, administration, health, etc. Based on a quantitative and qualitative analysis of the aforementioned "emergency" legislation, and drawing from international EBPM best practices, we propose some key recommendations with the aim of a course correction of the said process.

Our working hypothesis will also be tested through the "emergency legislation" of the 2020-2021 health crisis and after a relatively short period of "normality" following the formal end of the Memoranda (2018). Examining the regulations of another period of crisis, this time of public health and economy, we will try to identify whether there are continuities or discontinuities both in terms of the quality of policymaking and the corresponding structures. We claim that the enactment of this "emergency" legislation does not fulfill the requirements for designing and implementing sustainable public policies. It is the opposite of an integrated public policymaking paradigm which is based on documented data, social participation, and consensus, with effective planning and implementation procedures. Such a model would be Evidence-Based Policy Making (hereinafter: EBPM), which we will invoke as a fundamental (but regrettably deficient) condition for giving shape to a cohesive reform strategy in a country like Greece.

In what follows, we try to provide a positive answer to what we consider to be the substantive question, which is not "Why do reforms fail in Greece?" but rather "Could Greece design and implement reforms better?" To that aim, in Chapter 2 we provide a framework of analysis, namely the logic of a rational and documented policymaking as well as the data-policy connection -which was disregarded in all countries where adjustment programs have been imposed, thereby undermining the credibility and effectiveness of promoted reforms. To test the aforementioned working hypothesis regarding the "emergency regulation" throughout the multiple crisis period 2009-2021, in Chapter 3 we present the core of our research in a mixed methodological approach: a quantitative record of the crisis governments' regulatory philosophy to demonstrate through the application of specific indicators the poor quality of legislation ("patchwork" regulation). To achieve that, we compare the quality of legislation between two different crisis periods looking for continuities or differences. The first period concerns the legislative corpus of the pre-eminent period of the economic crisis, starting with the sovereign debt crisis of 2009-2010 and the first economic adjustment program (Memorandum of Understanding) until the signing of the third Memorandum by the first SYRIZA government elected under the banners of anti-austerity (thus including the Papandreou, Papademos, Samaras and the first Tsipras administration). Soon after the formal completion of the third Memorandum (August 2018), came the COVID-19 health crisis that again led 
to a state of "emergency legislation" by the Mitsotakis government this time - and which refers to the second period we are considering. We investigate the quality of regulation using specific indicators: (1) how many bills passed under the emergency legislation procedure, (2) how many Acts of Legislative Content were ratified by effectively bypassing the Parliament, and (3) whether these emergency legislative interventions contained purely financial and later public health-related provisions or if they simply became a vehicle for promoting all kind of regulations without following a due process of accountability and controls.

After this first part of the "evidence from Greece" (in terms of quality of regulation), in Chapter 4, we move on to the essence of Evidence-Based Policy Making, presenting also best practices from many countries with a certain tradition of EBPM (UK, Australia, USA). We also associate EBPM with Better Regulation practices as well as with the setting up of a strong Center of Government, which is a prerequisite for the introduction, institutionalization, and implementation of an EBPM logic in public policymaking (as in France). Then, in chapter 5, we present "evidence from Greece II" in terms of procedures and institutional structures. More precisely, we point out some steps in this direction that have taken place in crisis-ridden Greece since 2010 and until 2020, as well as the shortcomings and the barriers in the Greek case, while also drawing on a series of interviews with people (informants) who served as Secretaries-General in crucial ministries in all the crisis-era (2009-2019) and attempted to introduce EBPM functions. The presentation of the current situation leads us to formulate a modest policy proposal in the concluding chapter 6 , to enhance regulatory and policymaking efficiency in Greece, combining the philosophy of EBPM with Better Regulation and a powerful, coherent, and rationally structured Center of Government.

\section{A framework of analysis. Politics versus data: asymmetric relationship?}

Trust in government not only requires managerial pathways but also calls for procedures that ensure social consensus vis-à-vis intended reforms (Van de Walle \& Bouckaert, 2003). Furthermore, it depends on the ability of a government to design and implement its policies during transition periods (Ymeraj, 2018). Rothstein and Teorell conceptualize "quality of government" as a very specific version of impartiality, pointing out that it refers to "institutions that exercise government authority" (Rothstein \& Teorell, 2008).

It is precisely these preconditions of "quality of government" that were undermined in the years of the crisis, in a country like Greece that was marked by extensive "extra-institutional" ties between the state and the citizens (clientelism). An already pre-existing crisis of confidence towards the state- 
government institutions and national governments has been exacerbated to an impressive extent about Greece, although the same trend appears in all the crisis-ridden countries of the European South (Eurobarometer, 2009-2015).

A public policy, far from being static, is in itself a dynamic process, a constant production of opposing discourses, and entails a competition in mapping and conceptualizing a problem. In this competition various actors and networks of policymaking are involved, which include not only political actors, politicians, and parties but also lobbies, pressure groups or veto players, experts, policy entrepreneurs, media, civil society organizations (Muller \& Surel, 1998; Kingdon, 1984).

More specifically, part of the public policy literature focuses on the procedures of constituting the "evidence" (Nutley, Walter, Davies, 2007), on how the "evidence" is used or abused, on the difference between an ideal rationality and existing social reality (Pawson, 2006; Greenhalgh \& Russell, 2009; Marston \& Watts, 2003). It is a debate on the varieties and types of the information produced and taken into account (Solesbury, 2001; Head, 2008, 2010 and 2014; Heinrich, 2007), on the complexity of research tools and data (Cairney, 2014), on the relationship of the scientific community with the recipients of services (Johansson, Denvall, Vedung, 2015). In other words, "evidence" is a question of "translating" scientific knowledge and data into public policies (Ingold, 2016).

The debate, therefore, unfolds within but also outside the scientific community. The choice of "using" the scientific research depends on many different factors: the historical formation of a state's institutional mechanics, political choices which sometimes ignore the very evidence on which they originally sought to rely, the role and practices of the scientific community itself which is often called to frame the scientific knowledge with political narratives (Head, 2010; Nutley, Walter, Davies, 2007), the role of policy entrepreneurs but also political advisers (Roberts \& King, 1991; LSE GV314 Group, 2012).

It also relates to how a policy framework and analysis takes into account multiple variables and actors (Erkan, 2017), as well as the economic, social, and policy environments or simply the temporal dimension that may open "windows of opportunity" to transform the evidence into a tool that is likely to determine policy decisions (Cairney, 2017). As a result, the interaction between research and politics blurs the dividing lines, with the latter becoming more and more "scientific" and the former being more and more influenced by the necessities of public policymaking (Nutley, Walter, Davies, 2007).

Although chaotic, public policymaking is at the same time rational. Not in the sense of a perfectly rational model; Herbert Simon has catalytically pointed out the limits of any strictly rational approach via his concept of 
"bounded rationality" (Simon, 1991). Also, policymaking can never be considered as independent of politics; data and scientific analysis are never "crystal clear" and beyond politics (Hallsworth, Parker, Rutter, 2011). The positivist hypothesis that there may be a "science" of public policymaking is a feud. Nevertheless, data and strictly scientific analysis -in a word: "evidence"- can and should be a fundamental component of public policymaking; rational decision-making techniques can be something like the "checks and balances" of a strictly political understanding of public policy. Thus, Evidence-Based Policy Making constitutes such an approach, a variant of the classic cycle of public policymaking (problem definition, agenda setting, policy development, implementation, policy evaluation) that does not replace it but has a place next to and parallel with it.

\section{Evidence from Greece: a "patchwork" regulation in times of crisis}

Let us now present some evidence from the Greek case intending to test our hypothesis that such a policy-making philosophy is absent in Greece and thus undermines the state and polity's capacity to respond to crises and promote effective reforms. We take as an indicator of this absence the low quality of regulation, which escalates in times of crisis. Starting from the period of the economic crisis, the implementation of the policies contained in the three successive Memoranda went through legislative procedures that were too eager to adopt urgent draft laws or Acts of Legislative Content. Indeed, not only the basic "memorandum" laws were introduced to parliament under the urgent procedure, but so were many "secondary" implementation laws. Similarly, the Acts of Legislative Content, which are acts of bypassing parliamentary scrutiny, also increased significantly and therefore constitute an "exceptional" exertion of power by the executive.

The entire legislation from the adoption of the first Memorandum (May 2010) until the third (Law 4336/2015) constitutes a corpus of 515 legislative texts including international conventions and transposition of EU directives, statutory laws ratified via the normal but also the urgent parliamentary procedure, as well as Acts of Legislative Content. If we exclude the Acts of Legislative Content, it seems that the share of urgent drafts in the total in-crisis legislation is 5\%; if we compare this figure to the corresponding foregone share of urgent drafts in the period 1993-2009, which was just $0.5 \%$, the increase in extraordinary legislation in the years of the crisis is simply striking.

The whole picture becomes all the more striking if out of the total legislation we simply remove the international conventions and transposition of EU directives. Thus, taking into account only the statutory and implementation laws, the proportion of urgent drafts in the legislation as a whole rises to $9 \%$. Now, if we include the Acts of Legislative Content, the final result is quite impressive: $22 \%$ of the politically relevant legislation, i.e. 
over two out of ten draft laws, has been voted within 48 hours or just bypassing the legislative procedure!

Figure 1: Legislation in crisis: normal and urgent procedure (2010-2015)

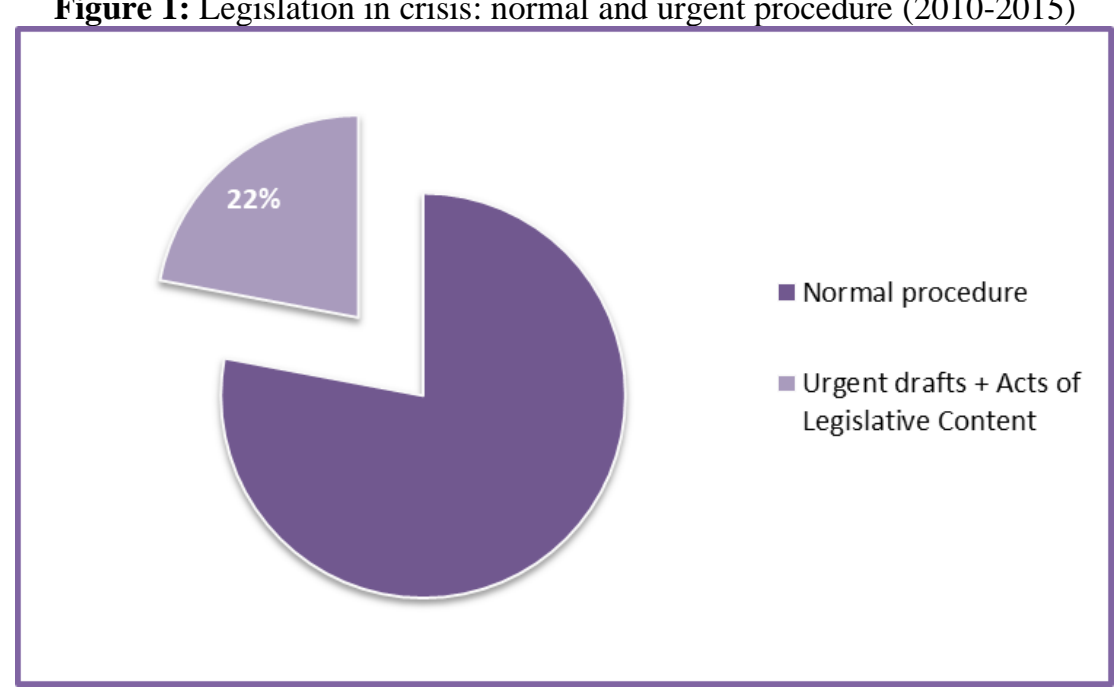

Source: Hellenic Parliament (legislation archive). Data processed by authors

The most crucial is that urgent bills have gradually become more and more of a "vehicle" for a series of regulations to be adopted by essentially circumventing parliamentary discussion, which is in no way related to the Memoranda imperatives. Out of a total of 27 bills voted by the urgent procedure as part of the implementation of the Memoranda agreements, 17 included provisions unrelated to their main (budgetary-fiscal) scope. In the same period, extremely extensive use of Acts of Legislative Content was made, reaching a total of 55. Of these, it is important to stress that that 21 were never even retrospectively sanctioned by the Parliament. Even more so, almost half of them (23 out of 55) also included regulations unrelated to their urgent scope -note well that the majority of those unrelated regulations were annexed to the Acts of Legislative Content with amendments proposed by ministers or MPs at the time of their ratification in Parliament.

Historicizing the legislative corpus of the crisis helps us record distinguishable periods and critical turns in this brief but dense period. The overall picture indicates that the Papandreou and Papademos governments have introduced and consolidated the extraordinary legislation (with 11 urgent bills each). However, it was the Papademos administration that seems to have consolidated this path not only in quantitative but also in qualitative terms: a practice of introducing irrelevant regulations into urgent bills and Acts of Legislative Content. This practice set an institutional path dependence from which the following governments did (and could) not deviate. Walking on this path, the government of Samaras has not only come to terms with this practice 
but reached its heyday, in absolute numbers of urgent bills but also with a striking analogy in favor of Acts of Legislative Content. In the same spirit, the first ("anti-memorandum") government of Alexis Tsipras of JanuarySeptember 2015, despite the previously intense denunciation of parliamentary derogations, joined the path and followed the same practice impressively, given its short life.

Figure 2: Acts of Legislative Content and Urgent drafts from the First to the Third Memorandum (2010-2015)

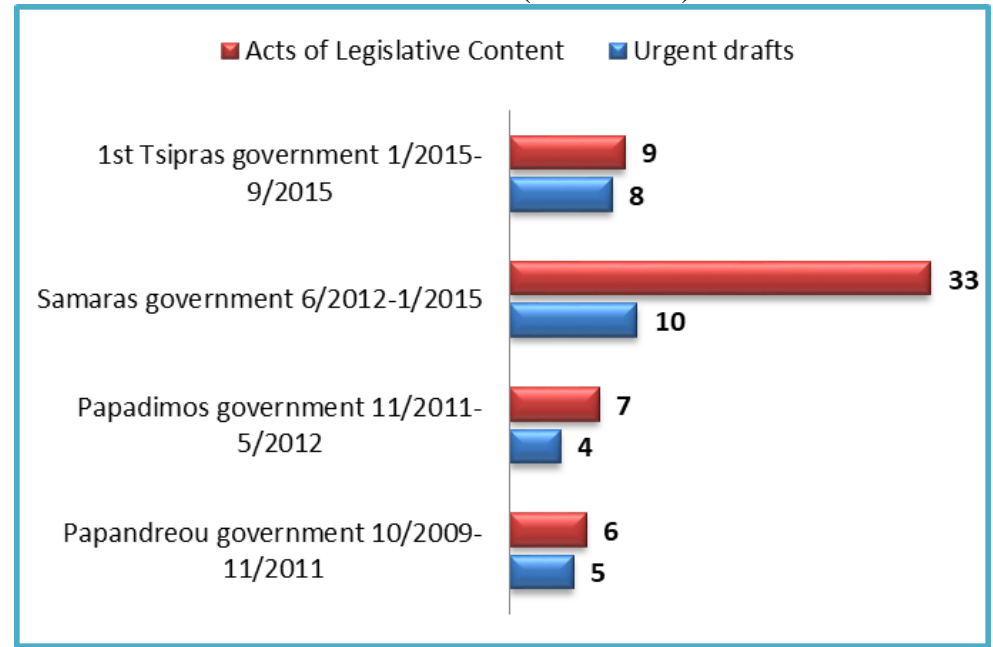

Source: Hellenic Parliament (legislation archive). Data processed by authors

This extraordinary lawmaking in the years of the crisis undermined the potential of introducing more rational planning and implementation of public policies. What's more, it was precisely this poorly designed and poorly prepared legislative practice that has (among other reasons) compromised the effectiveness of the "reforms" in the context of the adjustment programs. Memoranda were marked by many failings, actions, and measures that were either designed and never implemented, or their implementation lagged behind the original planning (especially tax and administrative reform) or even their results did not meet the expectations as they were often based on inaccurate data, risky forecasts and unrealistic assumptions (Katsimardos \& Bouas, 2013).

It would not be unreasonable to assume that this planning and implementation gap was directly linked to the low quality of the legislative process. It was rather a fatal combination: public policies/reforms violently imposed as an external shock, inherent vices of the Greek administrative and political elites, namely the lack of capacity to design and implement, and last but not least a "fast track" legislation used as passe-partout. Even more so, this explosive combination further undermined any confidence of the public towards the institutions and withered away any "quality of government" left, 
instead of reinforcing it as the necessary prerequisite to ensure a social consensus for the far-reaching reforms.

Let us now turn to the second period of "crisis regulation". The fiscal adjustment period formally ended in August 2018, with the completion of the third Memorandum. However, very soon, Greece, like the rest of the world, would find itself in the vortex of a new, different crisis: the COVID-19 pandemic. The Mitsotakis government, elected in the summer of 2019 with the promise of returning the country to "normalcy", was very quickly faced with a new state of emergency. It seems quite ironic that the first law passed in Parliament, in August 2019, was the Law 4622/2019, under the title "Executive State: organization, operation and transparency of the Government, government bodies and central public administration", through which the new government attempted to initiate a symbolic and institutional restart regarding Better Regulation and the Center of Government function. Starting from this very legislation, we examine here a total of 174 laws that were passed in the Greek parliament until May 2021. We can say in advance that the picture is very similar to the 2010-2015 period, although the financial crisis is not present and the health crisis concerns a specific issue (albeit a very vital one), without extending to an entire reform agenda such as the three Memoranda of the previous period. A first remark is that as in the previous period if out of the total legislation we simply remove the international conventions and transposition of EU directives, the proportion of urgent drafts, including the Acts of Legislative Content, reaches a not at all negligible 16\% - as compared to the $22 \%$ of the $2010-2015$ period. 
Figure 3: Legislation in COVID crisis: normal and urgent procedure (2019-2021)

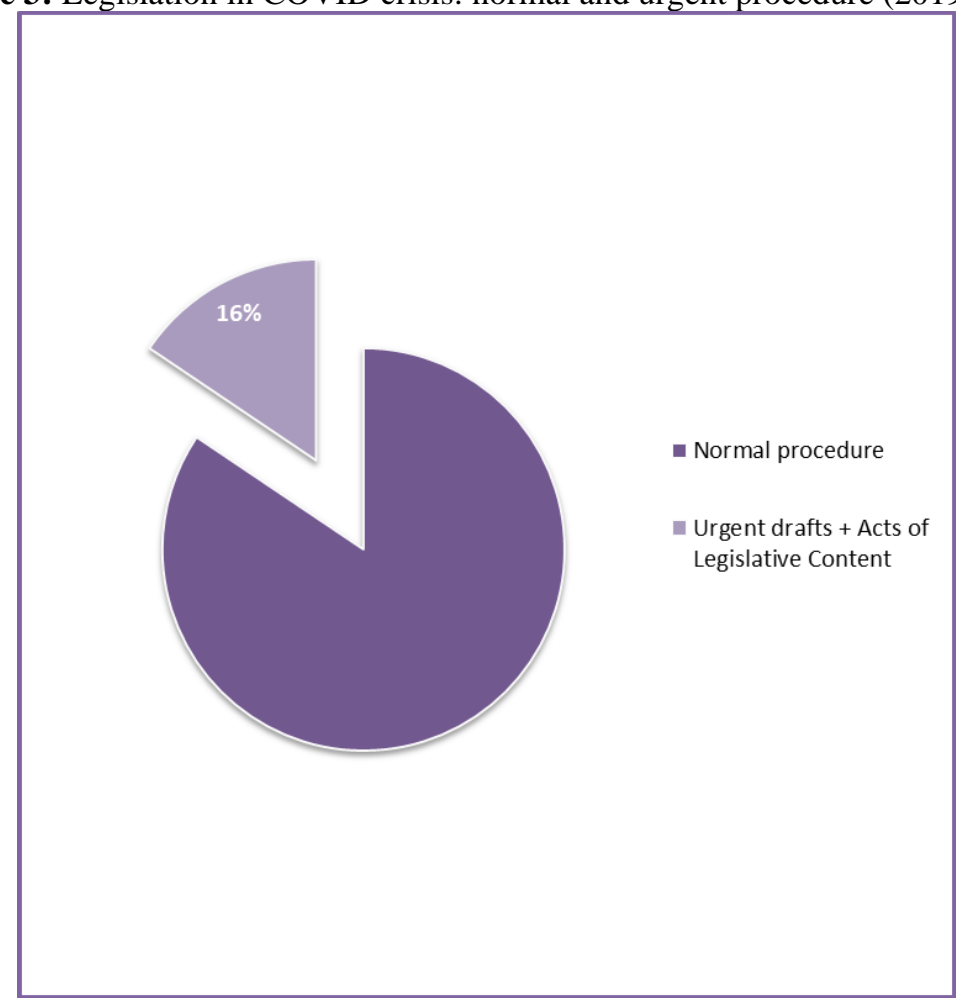

Source: Hellenic Parliament (legislation archive). Data processed by authors

At the same time, it seems that the pattern of the period 2010-2015 has been re-established, where urgent bills became the carrier of many regulations not at all related to the imperatives of the health crisis. Out of a total of 10 bills voted by the urgent procedure and 9 Acts of Legislative Content, all of them included without exception provisions unrelated to their main (supposedly health-based or else) scope. In terms of comparing this period with previous governments, Figure 4 below presents an updated version of Figure 2. It is clear here that the trend for extraordinary legislation has set an institutional path dependence also valid for the 2019-2021 period. 
Figure 4: Acts of Legislative Content and Urgent drafts from the First Memorandum to the COVID crisis (2010-2021)

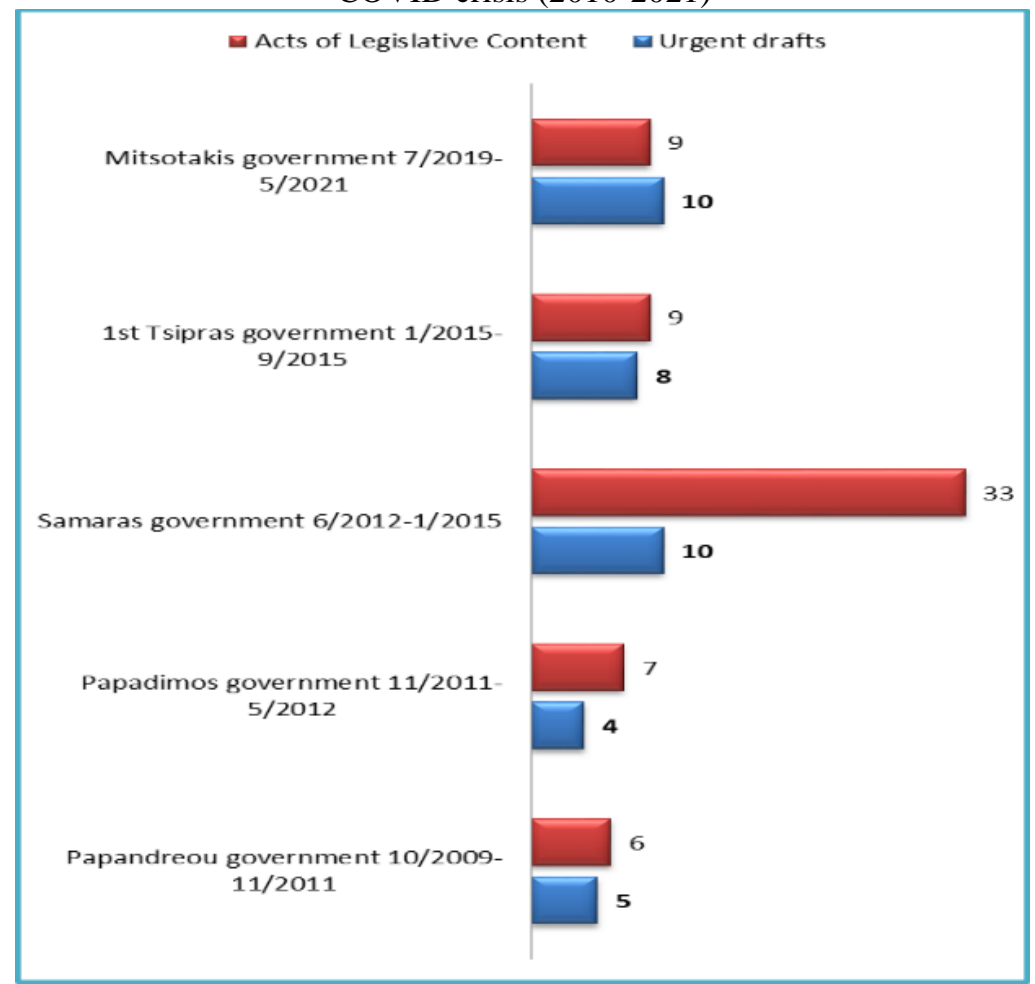

Source: Hellenic Parliament (legislation archive). Data processed by authors

Nevertheless, another aspect of regulation under conditions of crisis should be highlighted, this time with a positive mark in terms of quality of legislation. A crucial element of Better Regulation is the obligation for any regulatory intervention to be brought to the attention of citizens by employing a public consultation process. This, on the one hand, widens the circle of policymakers, as it involves views and proposals by all potential stakeholders, and on the other, facilitates the control of government regulation by citizens. The introduction of public consultation (on a relevant digital platform: OpenGov) constitutes one of the most successful innovations in the field of Better Regulation during the Greek crisis period. It has been adopted by all governments as a standard practice.

In Figure 5 we observe that the public consultation process is established by the pioneer in digital practices Papandreou government in 2009, shortly before the sovereign debt crisis. Already in 2010, the number of public consultations rises to 100 and despite the fluctuations (peak in 2016 reaching 120 consultations and lowest in 2015 falling to almost 60), it shows relative stability up to the year 2021 (for the year 2021 featured data reach up to May). The most critical indicator is the average duration of the consultation. Despite 
the legal obligation regarding the consultation to last for a minimum period, very often the possibility of shortening this deadline is used for reasons of "urgency" that are seldom justified. This practice of bypassing public consultation does not seem to greatly affect the overall positive picture, as the average duration of consultation does not fall under 15 days.

Figure 5: Public consultations and average duration per year (2009-2021)

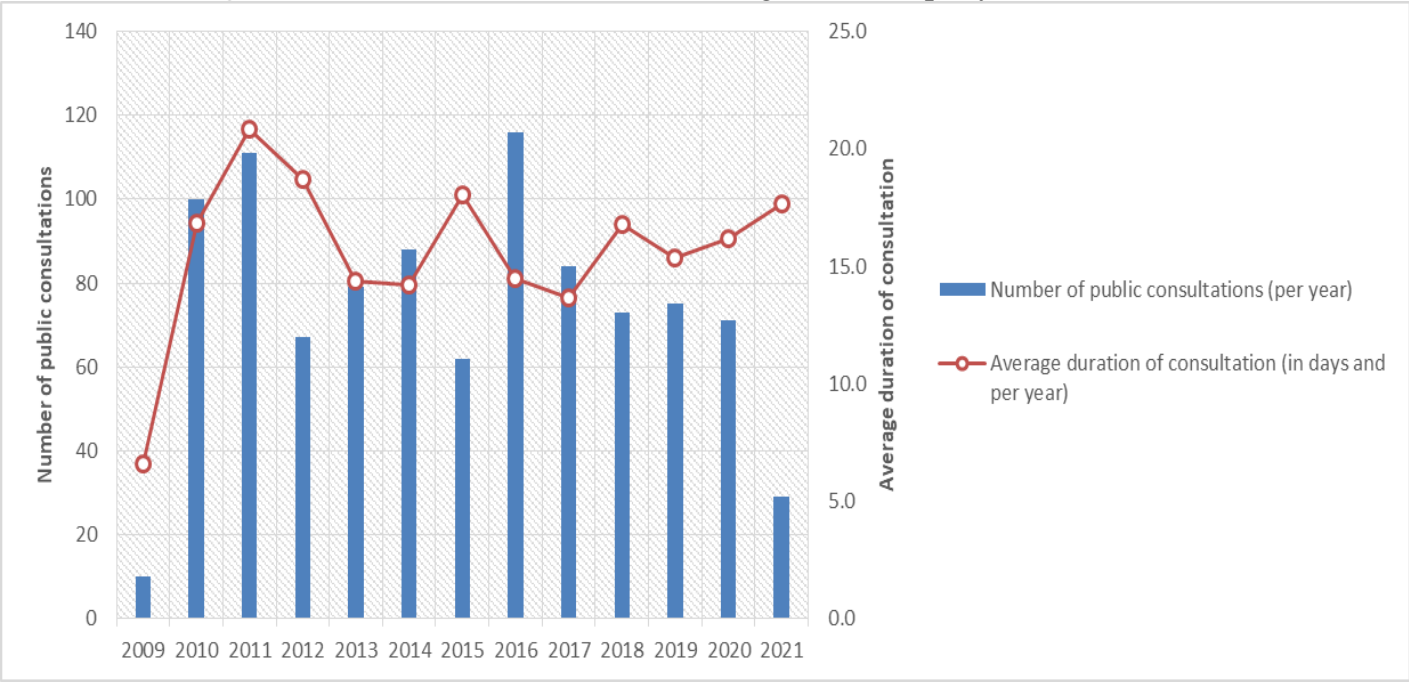

Source: www.opengov.gr (data processed by authors)

In fact, as Figure 6 shows, governments throughout the period under review are performing well in utilizing the tool of public consultation. Although the number of consultations is not always very telling (the Papademos government and the first Tsipras government did not last very long, hence the low number of consultations, while the Mitsotakis government is still in the middle of its term), the average duration shows that the proposed bills undergo a usually not less than 15 days open consultation with citizens, reaching up to 20 days in some cases. 
Figure 6: Public consultations and average duration per government (2009-2021)

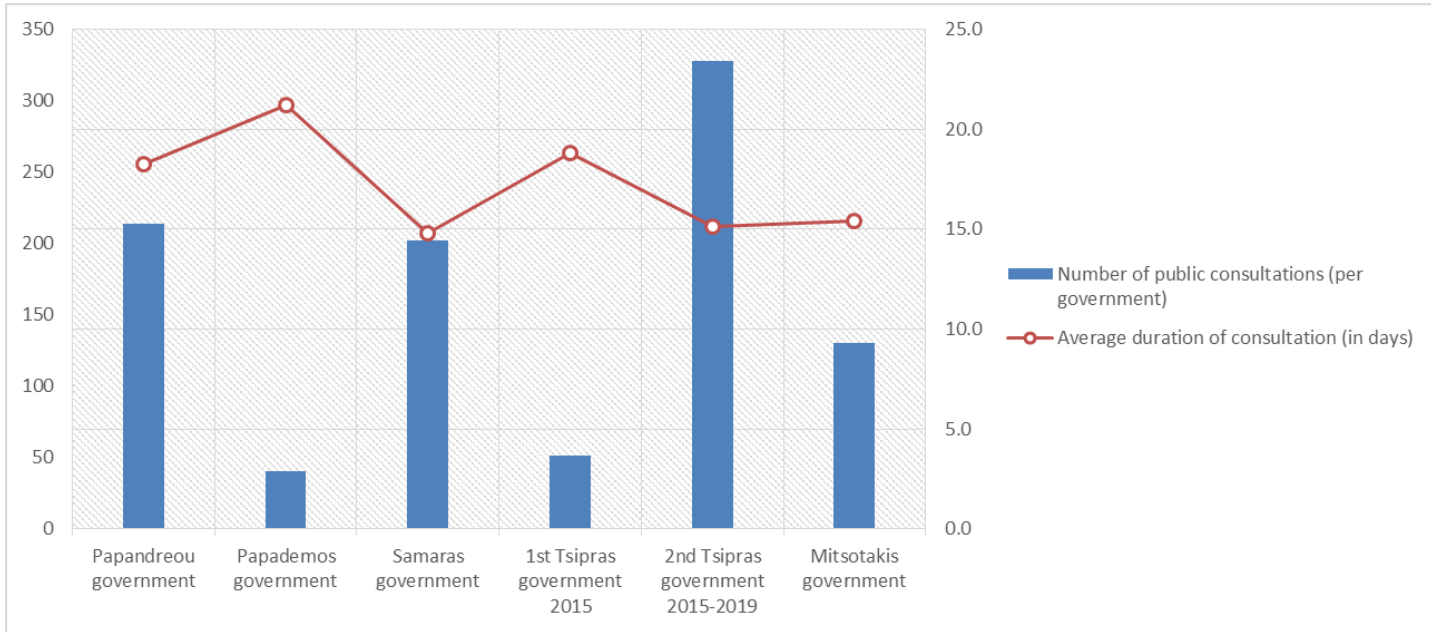

Source: www.opengov.gr (data processed by authors)

This positive aspect of Better Regulation does not negate the big picture of "patchwork" legislation, which although it existed well before the crisis, has intensified during the period under examination, undermining the credibility and effectiveness of reforms and public policy in general. Having presented the evidence from Greece in the field of Better Regulation, let us now (re-)turn to the institutional framework and good practices of EvidenceBased Policy Making, to evaluate relevant institutional changes that took place in Greece during the 2009-2021 period to improve regulatory governance.

\section{Evidence-based policy making: top-down and bottom-up}

The need to move from "management by intuition" to "data management" is not a new idea. At the EU level, it was already formulated at an informal meeting of public administration ministers in Vienna in 1988. But the EBPM model was implemented for the first time in Britain by the New Labor Government under Tony Blair in the second half of the 90s, with the simplistic, we could argue, slogan "What matters is what works." More recently, the EBRM method was widely used by the Obama administration in an attempt to redesign the overall system of federal programs, especially the welfare ones (Liebman, 2013).

The effort of the New Labor government was specific and clear: to release public policy from ideology's constraints, intuition, and mistakes of conventional wisdom. However, it has quickly been pointed out that such a view may be simplistic, as politics and ideology inevitably interfere with public policymaking, so that they can unconsciously even reverse the equilibrium condition, leading to the subordination of data to political necessities; thus, instead of a public policy based on data (evidence-based 
policy) we arrive at data steered by politics (policy-based evidence). Here are some prerequisites to avoid this risk:

$\checkmark$ a methodology that includes testing every theoretical analysis, based on the quantification of the data and the results of a proposed policy, etc.,

$\checkmark$ ensure reliable primary data and transparency in data processing,

$\checkmark$ ensure sufficient time -as it is argued that "evidence-building takes time" - and freedom of experts to formulate views that do not succumb to governmental constraints, and above all,

$\checkmark$ political leadership that will have the will to accept the findings of the experts and will use them productively and not just as a basis for justifying pre-judgments (Banks, 2009).

Additional relevant prerequisites would also include the extensive use of studies by scientists experts in each policy field together with their publication on dedicated government websites with open access for everyone concerned; Furthermore, it should encourage EBPM coordination at the highest intergovernmental level in a "whole-of-government" perspective (Radaelli \& Meuwese, 2008) as well as long-term public policy planning mechanisms by forward planning units (European Commission, 2015). These are the steps that lead from an "opinion-based policy" to an "evidence-based policy".

Apart from the UK, Australia is another country in which the relationship of politics to documented public policy planning has institutional depth. A series of units were instituted in the central government, responsible for collecting and utilizing statistics and indicators relating to areas such as industry, social welfare, health, and education (Head, 2014). The general context of documented public policy design over time has allowed for the emergence of "policy intellectuals", but also -as a result of a long-term public investment- for the consolidation of the size and potential of governmental organizations dealing exclusively with the collection of data, the analysis of public policies and their regulatory framework and other indicators (Head, 2014).

In continental Europe, public policy design processes are interlinked organically with Better Regulation procedures. France is a case in point. EBPM procedures have been systematically introduced in the context of a large-scale administrative reform (Révision générale des politiques publiques / RGPP), which started in 2007 and it is practically ongoing until today. The chain linking the whole process was the Council of Modernization of Public Policies (CMPP), an ad hoc body, in which the President of the Republic and the Prime Minister, the Minister of Finance and State Reform, and coresponsible ministers participate. Apart from the government's top, the RGPP 
also strongly encouraged the social dialogue processes in the context of improving regulatory governance in a country with a significant tradition in this field. The government has developed new methods of public consultation to effectively involve stakeholders each time, with a mix of traditional consultation methods through Advisory Bodies, such as in Britain, and innovations relating to online "e-consultation".

But how does Better Regulation engage with data-based policy design processes? Since the beginning of the RGPP in 2007, the General Secretariat of the Government has considerably broadened its scope for good lawmaking in France by strengthening the relevant Department of Law and Quality of Laws. The GSG has a key role in the process of Better Regulation. In addition, it is responsible for key competencies: it prepares the draft law files, it monitors the Impact Assessment process, it monitors all stages of the legislative process after passing laws, it controls secondary legislation, it is responsible for formulating the "Guide to Legislation and Regulatory Arrangements" in co-operation with the Council of State, it supports the European Affairs General Secretariat in its following the transportation of EU legislation, and finally it manages the Légifrance database that renders the whole of the French legislation accessible to citizens.

\section{Evidence from Greece II: structures and procedures}

In the previous chapters, we presented the fundamental logic behind EBPM as well as a variety of practical applications in countries with a relevant tradition, sometimes based on Better Regulation elements and with different degrees of governmental cohesion. Is it true that in Greece there are absolutely no elements of such an institutional logic? The answer is no. During the crisis, and next to the "patchwork emergency regulation" that we presented in Chapter 2, important steps have been taken in this direction. However, they remained fragmentary and largely without continuity and coherence within the tight constraints of the recovery plan. In this final part, we intend to describe these important steps, try to identify the weaknesses and gaps, and suggest some directions for adopting a more coherent process of evidence-based policy planning in Greece.

In 2011, the OECD report on the central government in Greece identified the need to establish a strong Center of Government as a structure safeguarding government vision and strategic planning as well as a supervising point of reference and accountability. The fundamental "malaise" of the Greek governance model is the excessive and ineffective legislative formalism at the expense of substantial policymaking. As public policies become more complex and interdependent, they have to be evaluated at an increasingly centralized level (OECD, 2011). 
In this direction, important steps have been taken, although much remains to be done. Indeed, in 2010 the Prime Minister's Office was upgraded to General Secretariat and was staffed with graduates of the National School of Public Administration and Local Government. Shortly thereafter, a separate Ministry of Administrative Reform and e-Government was established. Furthermore, Law 4048/2012 on Better Regulation has been adopted and a central unit of Better Regulation was established in the Government's Secretariat, along with horizontal Better Regulation and Financial Affairs units at the ministry level.

In the same direction, the General Secretariat for Coordination of the Government Program was established by Law 4109/2013, though without clearly defined responsibilities, as a key part of the Center of Government. Concurrently, the General Secretariat of the Prime Minister has attempted to introduce the concept of "evidence-based policy design", by explicitly declaring "both the co-operation of the central bodies and the inter-ministerial coordination to be a top priority in terms of its operational performance" (General Secretariat of the Prime Minister, 2012).

Realizing that Central Administration lacks management, supervisory, and coordination structures to support the effective implementation and longterm management of policy measures, some first steps were taken to develop a Government Program Monitoring System, which led to the implementation of the electronic platform DELOS. Originally handled by the General Secretariat of the Prime Minister and then by the General Secretariat of Coordination, DELOS aimed at supporting ministries in policy-making through interactive communication channels for all levels of government, the introduction of EBPM procedures, and emphasizing data with real and measurable results.

It is worth mentioning that EBPM tools were also attempted to be introduced with Law 4048/2012 on Better Regulation, which explicitly provided for regulators to communicate "in an open and editable form all the necessary data, in particular statistical, financial, environmental and spatial, which relate to and substantiate the proposed regulation", but also introduced innovative tools such as public consultation, regulatory impact analysis and evaluation of regulations' implementation effects (Law 4048/2012 on "Better Regulation").

Thus, the Center of Government in Greece, as shaped in the years 2009-2019, consisted of several subordinate structures with often overlapping competencies: the General Secretariat of the Prime Minister with a strategic role and the Vice President with a coordinating one; the General Secretariat of the Government with the main responsibility of supporting the work of the Government through coordinating structures, regulatory governance, and 
international affairs; the General Secretariat of Coordination with the task of coordinating actions for the implementation of government's program.

At the same time, several horizontal structures have been established in the individual ministries, where the scope of the Center of Government could be radiated outwards. These are the Ministries' Legislative Initiative Offices (which were first introduced in Law 4048/2012 with the main responsibility to participate in the drafting of legislation and regulations, the drafting of the bills assigned by the Minister and producing quality regulations), International and European Affairs Units, Strategic Planning Units, Directorates-General for Financial Services and e-Government units. However those are structures that do not communicate with each other or with the Center of Government, and also they are not homogeneous.

After the completion of the Memoranda period, and as mentioned above, literally the first legislative initiative of the newly elected Mitsotakis government in 2019, was Law 4622/2019 under the characteristic title: "Executive State: organization, operation and transparency of the Government, government bodies and central public administration". The new government symbolically tried to trigger an institutional restart with Better Regulation and a powerful Center of Government at its core. This law aims, as pointed out in the Explanatory Report (2019, p. 3) that accompanied the Bill during the process of its voting in Parliament, to become "the new integrated map of the Central Administrative System in Greece".

Let us examine a little bit further its main provisions. The Law 4622/2019 introduces a central strong Prime Minister "superstructure" (Karavokyris, 2020, p.14) with the establishment (article 21) of an autonomous, executive, public service, entitled "the Presidency of the Government", which reports to the Prime Minister and consists of different General Secretariats: General Secretariat of the Prime Minister, General Secretariat of Legal and Parliamentary Affairs, General Secretariat for Coordination of Internal Policies, General Secretariat for Coordination of Economic and Development Policies, Special Secretariat for an Integrated Information System of Monitoring and Evaluating Governmental Action, General Secretariat of Communication and Information.

The Principles of Better Regulation and Good Administration are described and defined (article 19) in terms of their content. Law 4622/2019 emphasizes the logic of Better Regulation (General Secretariat of Legal and Parliamentary Affairs, article 25) but also the monitoring, evaluation, and documentation of public policies through the operation of the Special Secretariat for an Integrated Information System of Monitoring and Evaluating Governmental Action (article 27). Especially regarding the issue of the documentation of public policies, within the Special Secretariat, there is an Office for the Evaluation and Documentation of Public Policies with 
various responsibilities and diverse obligations (article 27, paragraph 3). This heavily symbolic Law is characterized by the intention of "de-politicization" of the public administration. Mainly, because it introduces a clear distinction between administrative function and government (political) practice (Karavokyris, 2020, p.15).

In addition, the operation of the Executive State is incorporated and analyzed (articles 49 to 56), with a description of the planning process and monitoring of the government action and the recording of the annual government planning in the Consolidated Government Policy Plan, which is drawn up by the General Secretariats for Coordination of the Presidency of the Government and approved by the Ministerial Council of December each year (article 49). Particular emphasis is also given to the whole legislative process and again to the element of Better Regulation (articles 57-64).

Also, special attention is given to the auditing dimension of public policy by introducing a framework of obstacles, rules, and incompatibilities for Government members and various appointed officials (articles 68-76) and the establishment and operation (articles 82-103) of a new Independent Authority, the "National Transparency Authority", to strengthen accountability, integrity and combating corruption at all levels. Last but not least, an inter-ministerial branch of personnel is established with specialization in Public Policy Analysis, the Legislative process, and Digital Policy Analysis (article 104).

Nevertheless, one may argue that the Law's objective of "depoliticizing" the public administration emerges as a kind of panacea for remedying all sufferings of the Modern Greek state machine. This, however, alludes to an oversimplification of the administrative architecture's needs and procedures, under which a quite insidious risk lurks: the transformation of the term "executive state" (as it was also the case in the past with the term "reform") to a nom de guerre incorporating any possible mismanagement and adverse implementation of public policies during the health crisis.

Apart from the above sketchy and imperfect institutional steps, we should also refer to some sporadic individual attempts to introduce an evidence-based design that were made during this whole multi-crisis period. Rather than being a coherent effort, they relied on the initiatives of political personnel, while faced with numerous and different in nature obstacles.

Regarding the aforementioned points, useful information was provided to us by four General Secretaries, who served under different governments of the crisis, in their respective interviews. We chose to address General Secretaries on the one hand because their position crystallizes the intermediate level that links political leadership to the administrative mechanism and on the other. After all, all four of them have attempted to introduce elements of evidence-based public policy in the different policy fields they have managed. 
One key obstacle our informants have pointed out is that the introduction of this logic into an administrative and political mechanism like the Greek one, which is not "trained" in the documentation of the planned policy, takes time, which was not available given the urgent circumstances of the adaptation program. It is noted that at least at the level of the continuous negotiation, when the Greek side came up with evidence-based positions, it was met with better results in a joint design of the policy.

Nevertheless, the introduction of an EBPM process would come in conflict with a long-standing clientelistic tradition that is well suited to the "fabrication" of legislation, but would also contradict on the one hand a culture of public administration in Greece that resists integrating knowledge and information and on the other hand an "anything goes" culture of public management (Sotiropoulos, 2007; also supported by all our informants).

Administrative conditions are not always lacking; on the contrary, it is recognized that public administration human resources have units capable of producing studies, data, and documentation for use by the administration itself in public policy planning. What is lacking is an incentive-evaluation-reward system as well as an organized logic for the use of appropriate executives' inappropriate structures -which usually depends on the will of the political leadership, frequently resorting to the easy solution of external consultants.

The main question, however, revolves around an entire underlying institutional culture that has trampled the public administration to behave more formally from a regulatory point of view and without flexibility in the process of legislative production, ultimately giving priority to the formal production of legislation at the expense of public policy's implementation dimension. Our informants tried to introduce data through informal roads, in collaboration with both the administration and the research/academic community, with not negligible results, which however have not constituted an institutional memory that would bind the next political leadership.

Asked about the prerequisites of an EBPM logic, our informants acknowledged certain elements that have been mentioned earlier and which will be used in the following section to propose a coherent model of evidencebased public policymaking. The main argument that has been highlighted was the absence of a strong central mechanism that would coordinate, supervise, and have the political ground to impose on political leadership a commitment to coherent policy planning. During the crisis, this absence was more than evident, with dramatic implications, as fiscal policy in its entirety was designed and coordinated by the lenders of the country and not endogenously. An important role could also be played by existing institutions such as the National Center for Public Administration and Local Government (EKDDA). However, this requires a radical overhaul and expansion of the EKDDA's structure but also the overcoming of a rather bureaucratic operational logic. In 
addition, emphasis was placed by the informants on the consultation procedures that must accompany every legislative and reform effort and which may also have an informative role for the administration and the political leadership.

\section{Discussion and policy proposals: Tackling regulatory efficiency in Greece}

The quantitative and qualitative analysis of the "emergency" regulation of the period 2010-2021, as well as the analysis that followed the fallacies of the governance model in Greece, seems to validate the working hypothesis formulated at the beginning of this paper. Controversial regulatory quality and incoherent governance structures and culture prove to be largely ineffective in terms of public policy design.

The current model of governance in Greece, as described above and elliptic as it may be, is of course the first step; nevertheless, it is often nonoperational, and far from a coherent public policy process that incorporates the elements of Better Regulation and EBPM. It has three basic structural defects: (1) The Center of Government is fractured because it consists of different structures at the General Secretary level, with overlapping and sometimes inactive responsibilities, from 2009 to the recent "Executive State" of 2019; (2) although legislated to a significant extent, the requirements of Better Regulation, but more so of EBPM, are not binding at any stage of the regulatory governance, as indicated by the qualitative analysis of the "emergency" crisis regulation that we conducted for the whole period 20102021, and (3) the process is "introverted", with few obligations for deliberation and publicity (although public deliberation of proposed legislation works rather well, as we have seen above), so that the legislative process and policymaking remain a closed circuit process between ministries and parliament with minimum participation of civil society.

Correspondingly to the findings of our quantitative and qualitative analysis of crisis regulation and of system fallacies, but also on the basis of the aforementioned "menu" of applied EBRM practices, we may now present a modest proposal in the form of key recommendations enumerated below, that could eventually meet the fundamental requirements for a more coherent process adapted to the Greek institutional framework. This proposal offers, in addition, a solid, unhindered and reliable functional governance core beyond the constraints and contingencies of emergency and crisis imperatives.

1. First and foremost, a Unified and Efficient Center of Government is needed as the connecting link of the whole process, which despite some important steps that have been made, remains incoherent both in terms of administrative structures and in terms of "patchwork" legislation. A unified Center of Government would require a merging 
of different structures, such as the General Secretariat of Government and the General Secretariat of Coordination, into a single one (which in part has been implemented with the Law 4622/2019 on Executive State), closely linked to the horizontal structures of the ministries and the Legislative Initiative Offices and in particular through the appointment of senior officials as contact persons with the unified General Secretariat of Government Coordination. The comparative advantage and core mission of the Center of Government would be to supervise all government planning, especially at the ex post / ex-ante instance of evaluation of each ministry's initiatives regarding public policy areas, to ensure the quality of regulatory production (Better Regulation Practice with the cooperation of Ministries' Legislative Initiative Offices), to monitor the integration and implementation of EU law, cost-benefit analysis or individual aspects of each planned policy.

2. In this respect, the Legislative Initiative Offices should be the structures that will primarily and in principle draw up all the regulations of the Ministries, so that the proposed legislation would be more focused on the envisaged reforms and less "patchwork" in character (as it was the case with the "emergency" regulation, documented at the relevant part of the article).

3. In addition, and by enriching Better Regulation institutional framework, it would be important to establish more stages of preparliamentary Regulatory Impact Assessment (ESRC), with a Supervisory role for the Center of Government.

4. In this respect, it is necessary to widen and integrate an up-to-date DELOS platform with the aim of monitoring ministries' action plans at all stages and workflows of the (better) regulation process.

5. Corresponding to the pre-parliamentary impact assessment, the public deliberation should be extended in two phases (preliminary and final), to expand its scope and enhance civil society participation, which is not negligible as we have seen above.

6. At the stage of budgeting/cost-benefit analysis, the General Accounting Office could be actively involved in the process at a preliminary cost-benefit analysis of each proposed arrangement, as well as the Budget Office of the Parliament.

7. It is important to ensure the "participatory" dimension of the process, involving all necessary actors, social partners, and civil society organizations in the EBPM process. An institution such as the National Center for Public Administration and Local Government could undertake the role of centrally organizing all the necessary consultations/deliberations with institutional and informal advisory 
bodies, with social actors, specialists, and academic research centers (as our informants also suggested). The Documentation and Innovation Unit (MOTEC), which operates within the EKDDA and is responsible for the OpenGov deliberations, could be transformed into an open, comprehensive, and accessible portal of information, data, and scientific-administrative know-how, integrated into the EBPM policy design process.

8. Finally, in cases where regulatory production is directly linked to the country's international obligations, as was the case with the Memoranda of Understanding (Eurogroup meetings, loan disbursements, approvals of parliaments of Eurozone countries), the Better Regulation framework could be amended so that no Bill of Law would be introduced into the House in less than 15 days from the specified date, to ensure democratic control. The Center of Government can monitor these deadlines and guarantee the timely launch of the respective initiatives.

Some important steps in this direction have been made with the provisions of the recent Law 4622/2019, but its implementation seems to be erratic (at least in what concerns the quality of regulation, as indicated in Chapter 2 through the analysis of the "pandemic" regulation in 2020-2021). In any case, more steps need to be made in this path to guarantee a process and, above all, a different logic of planning and implementing public policy in Greece. Such a paradigm shift will set "security safeguards" in the legislative voluntarism of political leadership, introducing elements of documentation and intensive deliberation, as well as minimum prerequisites for the quality of regulatory governance. Moreover, it will eventually tackle the pathologies of public policy design, enhance efficient reforms and offer a better answer to the substantive question, as suggested by our working hypothesis, which is not "Why reforms fail" in Greece but rather if the country could, and in what terms, design and implement reforms better. Elements of Better Regulation and Evidence-Based Policy Making, together with an enhanced Center of Government and the EKDDA as a "hub" of evidence collection and public deliberation, could lead to a different paradigm. This paradigm will be situated well beyond the "emergency" policymaking in the crisis period, but also beyond the long-term pathologies of the Greek political and administration system, in which legislative formalism prevails at the expense of a coherent framework for planning and implementing public policies and reforms. 


\section{References:}

1. Banks, G. (2009). Evidence-based policy making: What is it? How do we get it? Canberra: (ANU Public Lecture Series, presented by ANZSOG, 4 February), Productivity Commission

2. Cairney, P. (2014). Evidence Based Policy Making: If You Want to Inject More Science into Policymaking You Need to Know the Science of Policymaking, Political Studies Association Annual Conference 2014, Manchester

3. Cairney, P. (2017). Why doesn't evidence win the day in policy and policymaking?, 22-2-2017, https://paulcairney.wordpress.com/2017/02/22/why-doesnt-evidencewin-the-day-in-policy-and-policymaking/ (last access: 10/10/2017)

4. Elster, J., Offe, C., \& Preuss, U., with Boenker, F. [et al.] (1998). Institutional design in post-communist societies: rebuilding the ship at sea. Cambridge: Cambridge University Press

5. Erkan, N. E. (2017). A Framework Proposal for Analysis of Urbanization Policy. European Scientific Journal, ESJ, 13(14), 24-30

6. European Commission. (2015). Quality of Public Administration. A Toolbox for Practitioners

7. Featherstone, K. (2005). Introduction: "Modernisation" and the Structural Constraints of Greek politics. West European Politics, 28(2), 223-241

8. Featherstone, K., \& Papadimitriou, D. (2010). The limits of

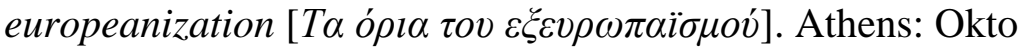
publishers

9. General Secretariat of the Prime Minister, Office of Strategic Planning. (2012). Summary of monitoring of the Government

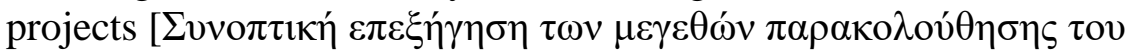

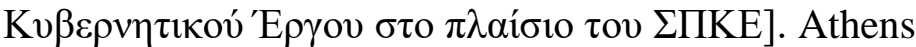

10. Greenhalgh, T., \& Russell, J. (2009). Evidence-Based Policymaking. A critique. Perspectives in Biology and Medicine, 52(2), 304-318

11. Hallsworth, M. (with Parker, S. \& Rutter, J.). (2011). Policy Making in the Real World. London: Institute for Government

12. Head, B.W. (2008). Three Lenses of Evidence-Based Policy. Australian Journal of Public Administration, 67(1), 1-11

13. Head, B.W. (2010). Reconsidering evidence-based policy: Key issues and challenges. Policy and Society, 29(2), editorial, 77-94

14. Head, B.W. (2014). Public administration and the promise of evidence-based policy: experience in and beyond Australia. Asia Pacific Journal of Public Administration, 36(1), 48-59 
15. Heinrich, C. J. (2007). Evidence-Based Policy and Performance Management Challenges and Prospects in Two Parallel Movements. The American Review of Public Administration, 37(3), 255-277

16. Ingold, J. (2016). Evidence-based policy and policy as 'translation': designing a model for policymaking, 22-7-2016, http://blogs.lse.ac.uk/politicsandpolicy/designing-a-model-forevidence-based-policymaking/ (last access: 10/10/2017)

17. Ioakimidis, P.C. (2001). The Europeanization of Greece: An Overall Assessment. In K. Featherstone, \& G. Kazamias (Eds.), Europeanization and the Southern Periphery. London: Frank Cass

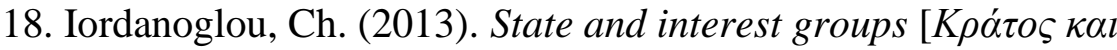
$o \mu \alpha \dot{\alpha} \delta \varsigma \sigma v \mu \varphi \varepsilon \rho o ́ v \tau \omega v]$. Athens: Polis publishers

19. Johansson, K., Denvall, V., Vedung, E. (2015). After the NPM Wave. Evidence-Based Practice and the Vanishing Client. Scandinavian Journal of Public Administration, 19(2), 69-88

20. Karavokyris, G. (2020). The executive State: rule of law and reform

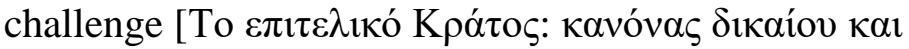

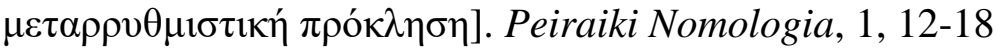

21. Katsimardos, P., \& Bouas., K. (2013). Memorandum as a policy tool. Strategic analysis and assessment of the large-scale reform programs

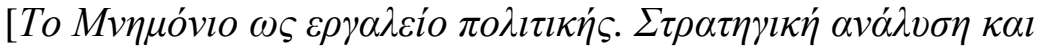

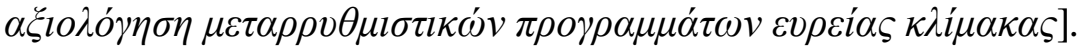
Athens: Institute of Research on Regulatory Policies

22. Kingdon, J. W. (1984). Agendas, Alternatives, and Public Policies. Boston: Little, Brown

23. Ladi, S. (2012). The Eurozone crisis and austerity politics: A trigger for administrative reform in Greece?. GreeSE Papers no 57, LSE, Hellenic Observatory

24. Law 4048/2012

25. Law 4109/2013

26. Law 4622/2019 and the accompanying to the Bill Explanatory Report

27. Liakaki, S., \& Balampanidis, I. (2019). Reforms in a crisis-ridden country. Public policy in Greece between state of emergency and

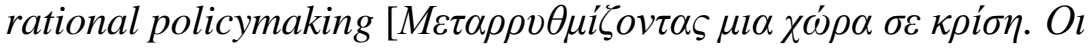

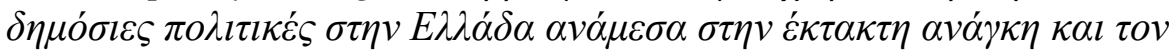

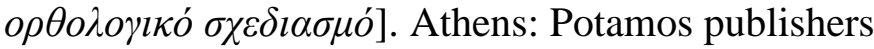

28. Liebman, J. (2013). Building on recent advances in evidence-based policymaking. Washington, DC: The Brookings Institution

29. Marston, G., \& Watts, R. (2003). Tampering With the Evidence: A Critical Appraisal of Evidence-Based PolicyMaking. The Drawing Board: An Australian Review of Public Affairs, 3(3), 143-163 
30. Mouzelis, N. (2005). Why reforms fail. The state and the party

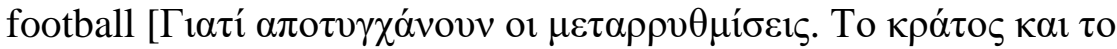

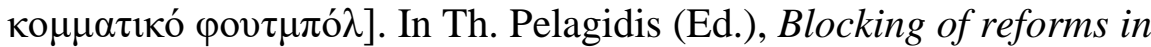

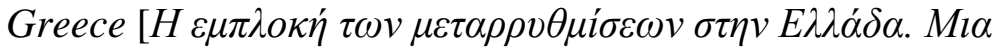

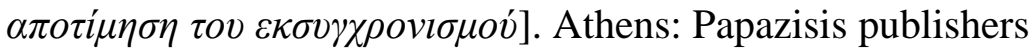

31. Muller, P., \& Surel, Y. (1998). L'analyse des politiques publiques. Paris: Montchrestien

32. Nutley, S. M., Walter, I., Davies, H.T.O. (2007). Using Evidence: How Research Can Inform Public Services. Bristol, UK: The Policy Press

33. OECD. (2011). Greece: Review of the Central Administration. OECD Publishing

34. Pawson, R. (2006). Evidence-Based Policy. A Realist Perspective. London: Sage Publications

35. Radaelli, C., \& Meuwese, A. C.M. (2008). Hard questions and equally hard solutions? Proceduralization through impact assessment in the EU. CONEX workshop on "Governing the EU: Policy instruments in a multi-level polity", Norwich

36. Roberts, N. C., King, P. J., (1991). Policy Entrepreneurs: Their Activity Structure and Function in the Policy Process. Journal of Public Administration Research and Theory, 1(2), 147-175

37. Rothstein, B., \& Teorell, J. (2008), What is Quality of Government? A Theory of Impartial Government Institutions. Governance: An International Journal of Policy, Administration, and Institutions, 21(2), 165-190

38. Simon, H. A. (1991). Bounded Rationality and Organizational Learning. Organization Science, 2(1), 125-134

39. Solesbury, W. (2001). Evidence Based Policy: Whence it Came and Where it's Going, Working Paper 1, ESRC UK Centre for Evidence Based Policy and Practice, London

40. Sotiropoulos, D. A. (2007). State and reforms in comtemporary

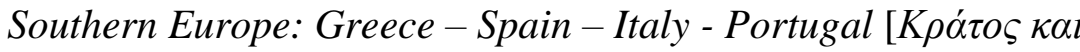

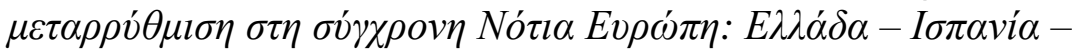

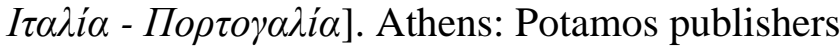

41. Standard Eurobarometer, waves 70 to 84 (2009-2015)

42. The LSE GV314 Group. (2012). New Life at the Top: Special Advisers in British Government. Parliamentary Affairs, 65(4), 715732

43. Tsebelis, G. (2002). Veto Players: How Political Institutions Work. New York: Russel Sage Foundation, Princeton University Press 
44. Van de Walle, S., \& Bouckaert, G. (2003). Public Service Performance and Trust in Government: The Problem of Causality. International Journal of Public Administration, 26(8-9), 891-913

45. Ymeraj, A. (2018). Government as a Key Duty Bearer in Transition Reforms from Socialism to Capitalism-The Case of Albania. European Scientific Journal, ESJ, 14(32), 84-101 